\title{
Protective effects of cisternal irrigation on leptomeningeal and cortical structures in meningitis: An experimental study
}

\author{
M. D. Aydin, C. Gündogdu*, F. Akçay* ${ }^{\star \star}$ N. Gursan* \\ Departments of Neurosurgery, *Pathology and ${ }^{* *}$ Biochemistry, Ataturk University, Erzurum, Turkey
}

\begin{abstract}
Background: Meningitis, termed as foreign material collection in the subarachnoid space, leads to various meningeal, cerebral and spinal cord pathologies. Meningitis still remains a problematic disease with severe complications in spite of advanced medical technology. Aims: In this study, we aimed to investigate the role of cisternal irrigation in the prevention of meningitis complications. Setting and Study Design: Experimental study was done in the Social Security Hospital of Erzurum. Histopathological specimens were evaluated in the Pathology Department in the Ataturk University Research Hospital, Erzurum, Turkey. Materials and Methods: This study was conducted on twelve lambs. Experimental meningitis was achieved with streptococcus pneumonia. Two animals were not treated. Ten animals were given Cefotaxime $^{R}(\mathbf{4} \times \mathbf{1} \mathbf{g} /$ day) for 20 days, and additionally half of these animals underwent cisternal irrigation. Then, all animals were sacrificed and brains were observed histopathologically. Results: Massive purulent CSF formation, hemorrhagic cortical lesions, vascular congestion, leptomeningeal and cortical adhesions and brain edema were observed in the non-irrigated group, but these findings were observed slightly or absent in the irrigated group. Conclusion: Meningitis can affect all central neural tissues, consequently serious central nervous system lesions may develop. The irrigation procedure may decrease the percentage and severity of meningitis complications by way of the excretion of inflammed purulent collection from the subarachnoid spaces.
\end{abstract}

Key Words: Experimental meningitis, irrigation, meningovascular changes

\section{Introduction}

Meningitis still remains a serious disease in spite of advanced treatment methods. ${ }^{[1]}$ It causes several life-threatening com- plications such as ventriculitis, ependymitis, focal encephalitis, hydrocephalus, porencephaly, multicystic encephalopathy, epilepsia, mental retardation, deafness and peripheral nerve palsies. ${ }^{[2,3]}$

The goal of therapy should be directed to the determination of etiologic agents. ${ }^{[1,4]}$ Purulent CSF has an increased viscosity and so is an excellent growth media for bacteria. We hypothesized that drainage of purulent CSF and its replacement may prevent complications of meningitis. To observe the effects of cisternal irrigation, experimental meningitis was produced and it was observed whether cisternal irrigation has a favorable effect in the treatment of meningitis.

\section{Materials and Methods}

This study was conducted on 12 lambs of 5-7 kg. All experiments were performed according to the guidelines for the ethical treatment of animals of the Atatürk University Research Hospital. All animals were anesthetized with $20 \mathrm{mg} / \mathrm{kg}$ of sodium penthobarbital for preoperative preparation. Thereafter, $0.2 \mathrm{~mL} / \mathrm{kg}$ of the anesthetic combination (Ketamine HCL, $150 \mathrm{mg} / 1.5 \mathrm{~mL}$; Xylazine HCL, 30 $\mathrm{mg} / 1.5 \mathrm{~mL}$; and distilled water, $1 \mathrm{~mL}$ ) was subcutaneously injected before surgery. Five $\mathrm{mL}$ of infected soluble material containing $10^{7} /$ $\mathrm{mL}$ streptococcus pneumonia was injected into the cisterna magna of animals. Animals were followed up for 25 days. Meningitis developed in all animals within 5 days. Two animals (Group I) were not treated for observing the effects of meninigitis. Ten animals (Group II, $n=5)$ were given Cefotaxime $(4 \mathrm{x} 1 \mathrm{~g} /$ day IV) for 20 days. Additionally, five of these animals were also given cisternal irrigation (Group III, $n=5$ ). We prepared an irrigation solution by mixing isotonic saline solution, dextrose solution (5\%) and distilled water at a ratio of 50/30/20, respectively. For irrigation, a $3 \mathrm{~F}$ catheter was permanently inserted into the cisterna magna through the foramen magnum and the other $3 \mathrm{~F}$ catheter was permanently placed in the subarachnoid space at the lumbar 4-5 level for 20 days. The irrigation was repeated 4-5 times a day for 20 days. During the irrigation, the animals were reanesthetized with the same combination used during catheter insertion.

After 25 days of the inoculation, all animals were sacrificed and 
their brains were scaled as follows: $(0=$ normal; $1=1-2$ lobes/brain; $2=$ all lobes/brain; $3=$ ventricles and all the brain are affected, $4=$ hydrocephalus development). After being kept in $10 \%$ formaline solution for 7 days, the brain sections were stained with H/E. Histopathological evaluation was performed by a blinded investigator. Histopathological appearances were scored as follows: Clear subarachnoidal space (0), vascular engorgement (1), vascular inflammation (2), massive purulent material collection in the subarachnoid space (3).

\section{Results}

Meningitis was fully developed in all animals within 5 days. The majority of all the infected animals had fever, epilepsy, paresia-plegia and sometimes consciousness. During therapy, clinical healing was accelerated in the irrigated animals. No animal died during the study period. Hemiplegia developed in two of the non-treated animals. Macroscopic examination of the brains showed massive swelling, abundant subarachnoidal purulent material collection, arachnoid-pia adhesions and serpinginious petechial cortical hemorrhage in Group II. Hydrocephalus was observed in 3 animals ( 2 from Group I, 1 from Group II (Table 1).

Histopathologically, the disease was characterized by purulent material collection in subarachnoidal and ventricular spaces together with meningovascular inflammation. An intense neutrophilic meningovascular inflammation was present in all animals in Group II. Some vessels and their branches showed marked dilatation and thrombosis. Reddish pus-like material covered, partly or totally, the surfaces of the brains.

\begin{tabular}{|c|c|c|c|c|c|}
\hline & 0 & 1 & 2 & 3 & 4 \\
\hline Group I (n=2) & - & - & - & - & 2 \\
\hline Group II (n=5) & - & - & 2 & 2 & 1 \\
\hline Group III $(n=5)$ & - & 3 & 1 & 1 & - \\
\hline
\end{tabular}

Massive infiltration of lymphocytes and neutrophilic polymorphonuclear leucocytes, a thick inflammed layer formation in the subarachnoid space, pia-cortex adhesion, sulcal stickiness and arterial thrombosis were also observed (Figure 1). Although meningeal and vascular inflammation persisted in nonirrigated animals (Figure 2), these findings were mild or not observed in the irrigated animals (Figure 3). Findings are summarized in Table 2. Histochemical parameters of the CSF (lymphocyte and mononuclear cells) also turned to normal.

\section{Discussion}

Meningitis is termed as a meningocerebral inflammatory response to purulent material collection in the subarachnoid and ventricular spaces. Meningitis results in cerebral ischemia, infarction, edema, cerebritis, abscess, hemorrhage, hydrocephalus and sometimes brain herniations. ${ }^{[2,5]}$ Bacterial meningitis commonly leads to death or severe neurological sequelae, including spastic or flaccid quadriparesis, mental retardation, cortical blindness, seizures and communicating hydrocephalus. ${ }^{[5]}$ Acute inflammation of the meninges, vascular involvement, meningeal adhesions were the histopathological hallmarks in our animal model.

Purulent CSF facilitates local bacterial growth and acts as a bacterial reservoir. The goal of therapy should be directed to an etiologic agent. Therefore, intraventricular drug administration is also advised. ${ }^{[1]}$ Meningitis is often accompanied by ventriculitis and the CSF has a pus-like appearance. Early drainage of CSF and intraventricular antibiotic therapy may

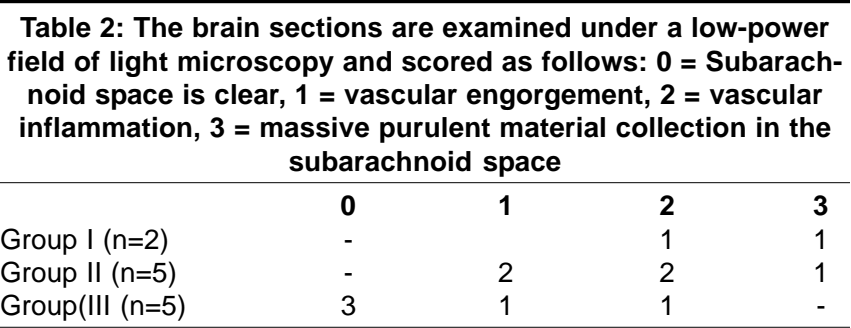
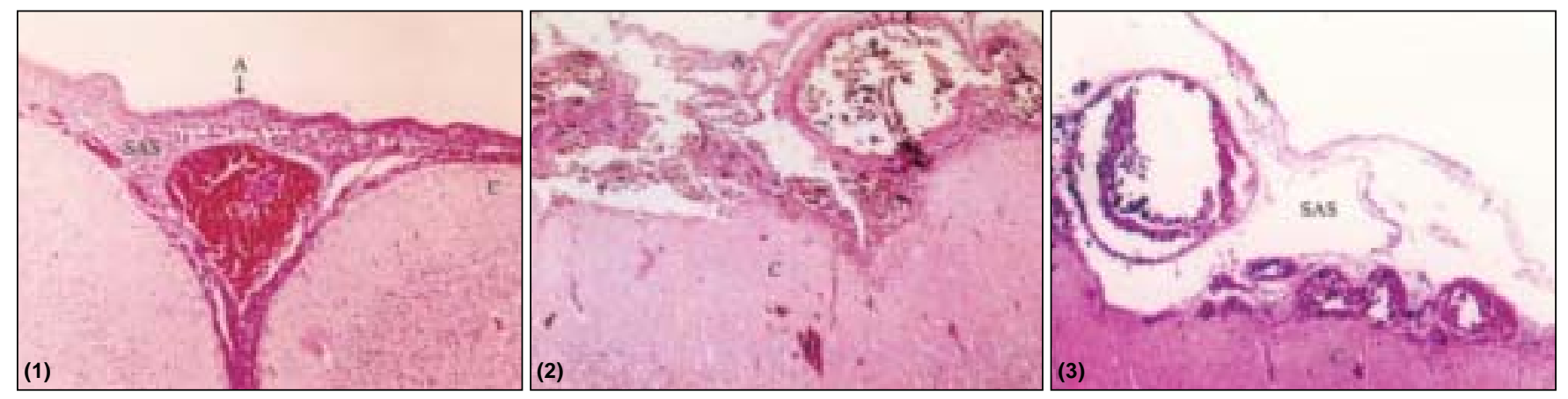

Figure 1: Massive infiltration of basophilic polymorphonuclear leucocytes, a thick inflammed layer formation in subarachnoid space, pia-cortex adhesion and vascular occlusions with inflamed material are observed in a nontreated animal (A: Arachnoid membrane, SAS: Subarachnoid space, OA: Occluded artery, C: Brain cortex) (LM, H/E,x40)

Figure 2: Mild degree subarachnoidal purulent material collection, pial infiltration and thickness, vascular congestion and thrombus formation are seen in antibiotherapy group (LM, H/E, x40)

Figure 3: Subarachnoid space is clear and vascular thrombus formation are seen moderately in the brain of irrigated group (LM, H/E, $\mathrm{x} 40$ ) 
produce a better outcome for meningitis. In intractable meningitis cases, a ventricular drainage-irrigation system may permit an adequate perfusion of the CSF together with an antibiotic to the subarachnoid space.

Continuous intraventricular irrigation in ventriculitis cases was reported in the previous studies. ${ }^{[6]}$ Meningitis may cause subarachnoid hemorrhage, and cisternal drainage can result in a rapid clearance of CSF in patients with subarachnoid hemorrhage. ${ }^{[7]}$ An intraventricular lavage was performed in post-traumatic ventriculitis and meningitis cases and it was repeated until the postoperative $7^{\text {th }}$ day and the CSF data improved immediately. ${ }^{[3,8,15,17]}$ It was also reported that ventricular lavage in combination with spinal drainage might result in a good outcome in such cases. ${ }^{[8]}$ After CSF clears, shunting procedure may be considered if hydrocephalus develops. ${ }^{[9]}$

Significant reduction occurs in CSF formation in ventriculitis due to inflammation of the choroid plexuses. Inflammation of the arteries and veins of the choroid plexuses may also lead to a decrease in CSF production, ${ }^{[10]}$ which in turn contribute to the occlusion of vessels and CSF circulation. Therefore, CSF replacement may prevent complications developing as a consequence of depleted CSF. ${ }^{[11-13]}$ The possibility of cerebral infarction is also significantly higher in patients without irrigation than in those with irrigation in ventriculitis, ${ }^{[14]}$ and such cases were treated with external ventricular drainage by Bayston et al. ${ }^{[15]}$ It was also reported that therapeutic intraventricular lavage could be performed in ventriculitis or hemorrhagic cases. ${ }^{[16-18]}$ It was claimed that irrigation therapies have been found to be effective in lysing subarachnoid clot and preventing vasospasm and infarction safely. ${ }^{[19]}$ Schmidt et $\mathrm{al}^{[20]}$ have shown that despite a reduction of CSF bacterial titers and leucocyte counts by CSF filtration, the extent of neuronal damage was unaltered in experimental streptococcal meningitis. Only antibiotherapy could not be completely sufficient for the meningitis. Therefore, we suggest cisternal irrigation together with spinal drainage until obtaining clear CSF. We think that irrigation and drainage not only remove foreign materials in the CSF but also prevent disturbances seen in cerebral circulation due to vasculo-occlusive factors observed in meningitis. Reduced CSF may cause subarachnoid space narrowing, arachnoid-piamater and vascular wall adhesions and arachnoid villus occlusions may result in circulation disorders both in blood and CSF circulation. Therefore, cisternal irrigation and CSF replacement procedure may prevent brain herniations by reducing the risk of hydrocephalus development and brain edema, and other complications seen in meningitis. The findings of this experimental study support and confirm the beneficial effects of the use of irrigation in the treatment of meningitis.

\section{References}

1. Schretlen E, Muytjens H, Slooff J. Neonatal meningitis, ventriculitis, intraventricular therapy or not? Tijdschr Kindergeneeskd 1985;53:136-41.

2. Breeze RE, McComb JG, Hyman S, Gilles FH. CSF production in acute ventriculitis. J Neurosurg 1989;70:619-22.

3. Statz A. Neonatal ventriculitis. A case report (author's transl). Monatsschr Kinderheilkd 1981;129:521-4.

4. Ferrieri P, Burke B, Nelson J. Production of bacteremia and meningitis in infant rats with group B streptococcal serotypes. Infect Immnol $1980 ; 27: 1023-32$.

5. Kim YS, Sheldon RA, Elliott BR, Liu Q, Ferriero DM, Tauber MG. Brain injury in experimental neonatal meningitis due to group B streptococei. J Neuropathol Exp Neurol 1995;54:531-9.

6. Ban S, Nagasawa S, Sato S, Chokyu M, Inutsuka N, Yamamoto T, et al. Experimental and clinical use of newly manufactured artificial cerebrospinal fluid (CSF) for continuous intraventricular irrigation in ventriculitis and intraventricular hemorrhage. No Shinkei Geka 1978;6:67-75.

7. Kodama N, Sasaki T, Kawakami M, Sato M, Asari J. Cisternal irrigation therapy with urokinase and ascorbic acid for prevention of vasospasm after aneurysmal subarachnoid hemorrhage. Outcome in 217 patients. Surg Neurol $2000 ; 53: 110-7$.

8. Wada T, Kuroda K, Yoshida Y, Moriguchi T, Nishikawa Y, Ogawa A, et al. A case of posttraumatic severe ventriculitis treated by intraventricular lavage. No Shinkei Geka 2000;28:737-43.

9. Mori K, Raimondi A.J. An analysis of external ventricular drainage as a treatment for infected shunts. Childs Brain 1975;1:243-50.

10. Cairns H, Russel DS. Cerebral arteritis and phlebitis in pneumococcal meningitis. J Pathol Bacteriol 1946;58:649-65.

11. Gao L. Care and observation of intraventricular drainage. Zhonghua Hu Li Za Zhi 1995;30:47-8.

12. Gerner-Smidt P, Stenager E, Kock-.Jensen C. Treatment of ventriculostomyrelated infections. Acta Neurochir 1988;91:47-9.

13. Humphreys RP. Surgical management of bacterial meningitis. Can Med Assoc J 1975;113:536-8.

14. Hirashima Y, Endo S, Horie Y, Kurimoto M. Indications for cisternal irrigation with urokinase in postoperative patients with aneurysmal subarachnoid haemorrhage. Br J Neurosurg 1996;10:477-81.

15. Bayston R, Hart CA, Barnicoat M. Intraventricular vancomycin in the treatment of ventriculitis associated with cerebrospinal fluid shunting and drainage. J Neurol Neurosurg Psychiatry 1987;50:1419-23.

16. Infection in Neurosurgery Working Party of the British Society for Antimicrobial Chemotherapy: The management of neurosurgical patients with postoperative bacterial or aseptic meningitis or external ventricular drain-associated ventriculitis. Br J Neurosurg 2000;14:7-12.

17. Ogata M, Nagata H, Sato S, Ban S, Chokyu M, Inutsuka N, et al. Endoscopie findings in ventriculitis and intraventricular hemorrhage and therapeutic intraventricular irrigation. Neurol Med Chir 1978;18:495-503.

18. Villarejo F.J. Postoperative ventriculitis in hydrocephalus: Treatment with external ventricular drainage. Acta Neurochir 1979;48:41-5.

19. Usui M, Saito N, Hoya K, Todo T. Vasospasm prevention with postoperative intrathecal thrombolytic therapy: A retrospective comparison of urokinase, tissue plasminogen activator, and cisternal drainage alone. Neurosurgery $1994 ; 3: 235-44$.

20. Schmidt H, Stuertz K, Trostdorf F, Chen V, Sadowski I, Bruck W, et al. Streptococeal meningitis: effect of CSF filtration on inflammation and neuronal damage. J Neurol 1999;246:1063-8.

Accepted on 19.01.2004. 